\title{
RESEARCH
}

\section{Object attraction and the role of structural hierarchy: Evidence from Persian}

\author{
Julie Franckㄹ, Farhad Mirdamadi and Arsalan Kahnemuyipour ${ }^{2}$ \\ 1 University of Geneva, Pont d'Arve, Geneva, $\mathrm{CH}$ \\ 2 University of Toronto Mississauga, CA \\ Corresponding author: Julie Franck (Julie.Franck@unige.ch)
}

\begin{abstract}
Research on subject-verb agreement production in SVO languages has shown that objects moved pre-verbally sometimes trigger attraction, i.e., erroneous agreement of the verb with the object rather than the subject. Moreover, objects c-commanding one of the agreement positions in the hierarchical structure were found to generate stronger attraction than those linearly preceding them. Evidence for the role of c-command comes from the observation that the accusative clitic in French triggers stronger attraction than the preverbal dative pronoun and the PP modifier (Franck et al. 2006; 2010). In this study, we report the results of an experiment in Persian (an SOV language) in which subject-verb agreement was elicited by presenting sentences in Rapid Serial Visual Presentation procedure (RSVP) followed by verb selection (Staub 2009; 2010). We compared attraction errors induced by pre-verbal accusatives versus datives in the canonical SOV word order as well as the OSV word order. Corroborating Franck et al. (2006; 2010), we found stronger attraction when the pre-verbal object occupies a c-commanding position in the hierarchical structure than when it simply precedes one of the agreement positions in the linear string. We also found stronger attraction in the OSV word order as compared to the canonical SOV word order. This finding is attributed to the real-time processes of erroneous structure building and/or erroneous controller selection during subject-verb agreement computation.
\end{abstract}

Keywords: Subject-verb agreement; Object attraction; C-command; Precedence; Intervention; AGREE

\section{Introduction}

In sentence production, a large body of research has been devoted to identifying the properties of a phenomenon called attraction. Attraction usually refers to the failure in number agreement between the sentential subject and the verb, due to the presence of a distracting element, mismatching in number with the subject head, and intervening on the subject-verb relation. The most common case of attraction is when the speaker incorrectly produces a verb that agrees with a plural noun situated in a modifying prepositional phrase (PP) linearly intervening between the subject and the verb (e.g., *The time for fun and games are over, taken from Bock \& Miller 1991). Nevertheless, other types of syntactic elements have the potential to trigger attraction. These elements include preverbal adjuncts (Franck et al. 2004); preverbal object clitics (Franck et al. 2006; 2010) but also elements that are not situated between the subject and the inflected verb in the linear order in constructions such as object relative clauses (Kimball \& Aissen 1971; Bock \& Miller 1991; Franck et al. 2006; 2010; 2015), object clefts (Franck et al. 2006), and questions (Vigliocco \& Nicol 1998).

It has been suggested that the hierarchical position of the intervening element modulates the strength of attraction (Franck et al. 2002), and more particularly, that c-command plays a key role in the phenomenon (Franck et al. 2006; 2010; 2015). However, the role 
of hierarchical structure in attraction has been questioned (Gillespie \& Pearlmutter 2013), and experimental evidence available to-date about the role of c-command is restricted to French, and potentially contradicted by data reported in Dutch (Hartsuiker et al. 2001). In this study, we examine the role of hierarchical structure and more particularly c-command in object attraction in Persian. Persian allowed us to further explore, within minimal-pair experimental conditions, the role of these factors in two structurally different test cases: one involving preverbal objects (SOV) and one involving fronted objects (OSV). In the remainder of the introduction, we first briefly review the literature on the role of hierarchical structure and the debates in this respect. We then discuss some key aspects of Persian syntax that are necessary for the current study. We end the introduction with a description of the current study.

\subsection{Hierarchical structure in attraction: The debate}

The possible role of syntactic structure in attraction was suggested early on in the attraction literature. Bock and Cutting (1992) were probably the first to draw attention to the role of hierarchical structure in attraction. They did so on the basis of their findings that attractors situated in a prepositional phrase modifier, i.e., within the same clause as the subject head (e.g., *The editor of the history books were old), triggered stronger attraction than those situated in a separate clause, like a relative clause or a complement clause modifier (e.g., *The editor that rejected the books were old). Although the attractor books occupies a similar position in the linear word string, its impact appears to vary with its structural position, which led the authors to argue that production units during sentence planning are organized in "clausal packages" such that elements outside of the subject clause are less susceptible to generate attraction, due to the fact that they are not planned at the same time and thus less prone to interfere with the planning process. Further evidence for the role of syntactic structure in attraction came from Vigliocco and Nicol (1998), who found similar attraction rates when the attractor linearly intervenes between the subject and the verb (e.g., *The helicopter for the flights are safe) and when it does not, as is the case in the corresponding interrogative structure (e.g., *Are the helicopter for the flights safe?). Interestingly, attraction is much reduced in Italian structures involving free inversion, which are superficially similar to interrogatives (the linear order is also: Verb - Subject head - Subject modifier), but structurally different (Franck et al. 2006). That is, whereas similar structures with different linear orders give rise to similar attraction rates (declaratives and interrogatives), different structures with similar linear orders give rise to different attraction rates (interrogatives and free inversion). Moreover, Franck et al. (2002) found that when the complex subject contains two PP modifiers (e.g., The helicopter for the flights over the canyons), the structurally higher modifier triggers the strongest attraction, despite being linearly distant from the verb. In sum, the linear distance between the attractor noun and the verb does not appear to capture a variety of data sets, which can be captured by reference to syntactic structure (see Franck 2010; 2017 for further discussion).

Initial evidence for the more specific role of c-command came from observations in French showing that the pre-verbal accusative clitic ((1a) below) generates stronger attraction than the dative clitic (1b) and the subject modifier (1c), the latter two generating similar levels of attraction (Franck et al. 2006; 2010). Throughout the paper, agreement errors are indicated with an asterisk at the beginning of the example sentence.

a. *Le professeur les lisent.

the.SG teacher.SG them.ACC.PL read.PL

'The teacher reads them.' 

b. *Le costume leur conviennent. the.SG costume.SG to-them.DAT.PL suit.PL 'The costume suits them.'
c. *Le professeur des élèves lisent. the.SG teacher.SG of-the.PL students.PL read.PL 'The teacher of the students reads.'

Franck et al. (2006; 2010) based their analysis of attraction on the formal mechanisms of sentence derivation described in generative syntax. In generative syntax, the generation of syntactic dependencies (e.g., subject-verb agreement) is viewed as a succession of formal operations such as Merge, Agree, and Move. Merge puts two elements together to construct bigger constituents. Successive applications of Merge assemble the thematic nucleus of the sentence. Further applications of Merge introduce a fully-fledged hierarchical skeleton whereby the subject enters into an Agree relation with T (Tense). The Agree relation is established through some formal mechanisms in which feature uninterpretability plays a crucial role. $\mathrm{T}$, the probe of Agree, contains uninterpretable phi features including number, person, and gender. It establishes an Agree relation with the subject in the specifier of vP, by which the unvalued phi features of T get valued. In some languages, e.g. English or French, this Agree relation is coupled with the movement of the subject to the specifier of TP. Once in that specifier position, arguably a new spec-head relation is established, between the subject and the verb. Franck et al. (2006; 2010; 2015) argued that both the Agree relation and the spec-head relation were sensitive to intervention effects. Intervention is a central concept of the theory of locality referred to as Relativized Minimality (RM), which defines it in the following terms: in a structure like [X ... Z ... Y] the local relation between $\mathrm{X}$ and $\mathrm{Y}$ is disrupted when: (i) $\mathrm{Z}$ structurally intervenes between $\mathrm{X}$ and $\mathrm{Y}$ in terms of c-command; (ii) $\mathrm{Z}$ matches the specification in morpho-syntactic features of $Y$ (Rizzi 1990). However, in contrast to RM according to which $Z$ disrupts the local relation between $\mathrm{X}$ and $\mathrm{Y}$ if and only if Z c-commands Y, Franck et al. (2006) hypothesized that any type of intervention was able to perturb agreement computation, although c-command intervention has a stronger effect than precedence (linear) intervention. The rationale behind that hypothesis was that in contrast to RM, which is a theory of grammar, a theory of agreement computation necessarily entails error-prone performance systems. In particular, it seemed reasonable to assume that linear intervention has the potential to mislead the system (although to a lesser extent), given the fact that an element that precedes another element often c-commands it. Hence, as Rizzi (2013: 75) formulated it: "Precedence offers a rough, imperfect but not totally unreliable cue for structural prominence and c-command. Therefore, it is not surprising that performance systems, bound to function under time pressure, use this cue, and are sometimes misled by it." In this view, processes involved in agreement computation (and its derailments) are fundamentally grammar-driven, such that grammatical factors like c-command play a key role in their realization; however, they may also show sensitivity to non-grammatical influences, due to external constraints on their operation (see the general discussion for a finer description of the assumptions about the role of memory in agreement processing).

Although that model is primarily concerned with identifying the representational (configurational) conditions under which attraction arises and is modulated, Franck et al. (2010) assumed that the mechanism underlying agreement processing is a mechanism of feature copy, in some respects similar to that assumed in the Marking and Morphing model (Eberhard et al. 2005) or the Feature Selection and Feature Copy model of Franck et al. (2008; see also Franck 2017, for further developments of the model): features from an agreement source are copied to an agreement target, by virtue of their dependency in 
the hierarchical structure. In this view, attraction arises when the attractor's feature is erroneously copied onto the agreement target due to its intervention on either Agree or Spec-head. In this model, intervention is a necessary condition for a copying error to arise, and intervention, which may include intermediate traces, is defined on the hierarchical structure based on Kayne (1989; 1994).

Let us now examine how this framework captures the data from Franck et al. (2010). It is commonly assumed that the clitic is base-generated post-verbally in French but undergoes movement and transits through the specifier of the object agreement phrase AgrOP (Kayne 1989), intervening on the Agree relation between T and the subject. Franck et al. (2010) argued that the accusative clitic occupies a position, spec of AgrOP, intervening by c-command on Agree as the accusative clitic c-commands the subject when it is still in the spec vP position. In contrast, they argued that the dative intervenes from a position of precedence without c-commanding the subject, as it is embedded inside a Prepositional Phrase layer (PP), in a way similar to the subject modifier. They reasoned along the following lines. First, they argued that clitic attraction arises when they intervene on Agree, and not when they intervene on Spec-head. Evidence in support of that claim is their finding that object clitics do not trigger more attraction than full object NPs moved preverbally, as would be expected if the former generated attraction at both levels. Moreover, clitics, once they intervene on Spec-head, are of a different structural type from the subject head, which would prevent any intervention effect. The authors argued that indeed, at the intermediate stage of the derivation when the displaced object occupies the AgrO position intervening on Agree, the object is still a phrasal entity, that is, an element of the same type as the subject. Evidence for that claim comes from the fact that quantifiers like tous accompanying the object can either be stranded in the initial object position (e.g., Le professeur les a lus tous, 'The professor them has read all') or move to the intermediate position AgrO (e.g., Le professeur les a tous lus, 'The professor them has all read'), suggesting that the object has moved as a full NP in that position. To complete the argument, Franck et al. (2010) argued that at the level of the intermediate AgrO position, the preposition introducing the dative object is still present, as it is stranded with the quantifier (e.g., Le professeur leur a à tous lu, 'The professor to-them has read to all read'). Hence, at the stage of the derivation where the object clitics are thought to intervene on agreement, the dative is still embedded within a prepositional layer, such that it only intervenes by precedence, which explains why similar attraction rates were found with PP modifiers. The intervention of the accusative clitic and the dative clitic on the Agree relation linking the subject in vP and T is illustrated in (2) schematically. In (2a), at the point of the derivation when $\mathrm{T}$ establishes an Agree relation with the subject in SpecvP, the intervening accusative clitic in SpecAgrOP c-commands the subject. In (2b), however, the intervening dative clitic is inside the PP and does not c-command the subject. Note that $<>$ manifests the copies of the subject and the clitics in their base positions.

a. The intervention of the accusative clitic by c-command

$\left[{ }_{\mathrm{TP}}\right.$ subject $\left[\mathrm{T} \ldots\left[_{\mathrm{AgrOP}}\right.\right.$ acc clitic ... $\left[_{\mathrm{vP}}<\right.$ subject $>\ldots[\mathrm{v}<$ acc clitic $\left.\left.\left.\left.>]\right]\right]\right]\right]$

b. The intervention of the dative clitic by precedence

$\left[{ }_{\mathrm{TP}}\right.$ subject $\left[\mathrm{T} \ldots\left[_{\mathrm{AgrOP}}\left[_{\mathrm{PP}} \mathrm{P}[\right.\right.\right.$ dative clitic $\left.]\right] \ldots\left[_{\mathrm{vP}}<\right.$ subject $>\ldots\left[\mathrm{v}\left[_{\mathrm{pp}}\right.\right.$ $\mathrm{P}[<$ dative clitic $>]]]]]]$

Additional evidence in support of the role of c-command comes from another set of results in French showing that the head of a moved complex object generates more attraction (as in 3a) than its complement (as in 3b, Franck et al. 2015). Here again, the attractor intervenes in Agree by c-commanding the subject in its base position, whereas it only 
intervenes by preceding the subject in (3b), due to the fact that it is embedded within a prepositional layer.

a. *Quelles patientes du médecin dis-tu que le which.PL patients.PL of the.SG doctor.SG say-you that the.SG juriste défendent? lawyer.SG defend.PL?

'Which patients of the doctor do you say that the lawyer defends?'

b. "Le médecin de quelles patientes dis-tu que le the.SG doctor.SG of which.PL patients.PL say-you that the.SG juriste défendent? lawyer.SG defend.PL? 'The doctor of which patients do you say that the lawyer defends?'

However, three sets of empirical evidence were argued to question the role of hierarchical structure in attraction. The first set comes from work by Gillespie \& Pearlmutter (2013), who contrasted sentences similar to Franck et al. (2002) with a nested structure, in which the second PP modified the first PP (e.g., The backpack with the plastic buckles on the leather strap), to sentences with a flat structure in which both PPs modified the head (e.g., The highway to the western suburbs with the steel guardrail). They found no difference between the descending and flat structures: both generated stronger attraction with the first PP, which made the authors conclude that hierarchical structure played no role in attraction. On the basis of additional results showing that the stronger attraction with the higher PP was only found when it was more integrated semantically with the head than the lower PP, the authors proposed that attraction is determined by a combination of both linear distance and semantic integration with the head. They argued that these two factors affect sentence planning: attractors that are linearly closer to the head and/or semantically integrated with it tend to be planned at the same time as the head, such that the two are simultaneously active in memory and their numbers have increased chance to interfere. The second set comes from the finding by Gillespie \& Pearlmutter (2013) that, once sentences with intervening PP modifiers and those with intervening relative clauses are matched for content words and semantic content, similar attraction arises in the two structures (contra Bock \& Cutting 1992), again arguing against an influence from hierarchical structure. Finally, Hartsuiker et al. (2001) contrasted sentences in Dutch like (4a) and (4b), and found that preverbal accusative objects (as in 4a) generate less attraction than PP modifiers (as in 4b). This pattern is opposite to what was found in French. Franck et al. (2010) suggested that the discrepancy could be captured if one assumes that in Dutch, being SOV, the object in its base position does not intervene by c-command on the Agree relation between the subject in the spec VP and T (... [T [Subj [VP [Obj V]]]]...), since the object fills a low position in the structure. The finding that the accusative object in Dutch triggered even less attraction than the PP modifier was explained by the fact that the object is more deeply embedded, such as the configuration with double modifiers in Franck et al. (2002), in which depth of embedding was found to reduce attraction.
a. *Karin zegt dat het meisje de kransen winnen. Karen says that the girl.SG the garlands.ACC.PL win.PL 'Karen says that the girl wins the garlands.'

b. *Karin zegt dat het meisje met de kransen winnen. Karen says that the girl.SG with the garlands.PL win.PL 'Karen says that the girl with the garlands wins.' 
In sum, although various experimental reports support the hypothesis that syntactic structure, and more specifically hierarchical depth and c-command, play a significant role in modulating attraction, some sets of empirical evidence question that conclusion. With regard to the data provided by Gillespie \& Pearlmutter (2013), we note that the conclusion against hierarchical structure entirely relies on lack of effects. Nevertheless, additional empirical evidence is needed to validate the role of c-command. Indeed, the test cases supporting its role (Franck et al. 2010; 2015) have weaknesses. First, there is an apparent contradiction between the French data and the Dutch data: more attraction was found with PPs than with accusative objects in French, while the opposite was found in Dutch. Although an interpretation of this divergence has been proposed, it relies on various non-obvious theoretical assumptions. Moreover, the cross-linguistic comparison is imperfect: French involved clitics in object position whereas Dutch involved full noun phrases embedded in PP modifiers; objects and PPs do not only differ in terms of c-command, they crucially differ in that the latter are part of the subject constituent in the hierarchical structure whereas the former are not. Second, the two test cases contrasting precedence and c-command within minimal pairs have been studied in French only; there is to-date no cross-linguistic validation of the observations. Third, the two test cases of object attraction explored in French involved objects in non-canonical positions (preverbal clitics and fronted NPs). Given the special status of non-canonical structures (in both linguistic and psycholinguistic theory), it is important to determine whether the effect arises in canonical structures. Persian, an SOV language, like Dutch, allowed us to address these weaknesses by contrasting dative and accusative NPs both in their canonical position and in a non-canonical fronted position. We describe the relevant properties of Persian in the following section.

\subsection{Key aspects of Persian syntax}

We discuss here the analysis of two related properties of Persian that are relevant to our study, namely its word order and the position of the accusative and dative objects. The underlying position of the object is generally a matter of debate in any SOV language including Persian. Kayne (1994) argued that SOV is derived from an underlying SVO order. Based on Kayne's analysis, the object moves from the VO order to the pre-verbal position to receive case in a specifier-head configuration. To obtain the canonical SOV word order in Persian, one could assume that the subject is merged in the specvP and then is raised to the spec-TP after the Agree relation is established. The object is moved from the post-verbal position to the specifier of a functional projection above the verb. As for the position of the verb in the hierarchical structure, there are two options: the verb could remain in-situ (Karimi 2005) or could raise to a head position above V but below $\mathrm{V}$ (Travis's 1991 Asp(ect) head, see Kahnemuyipour 2009), rendering an SOV order. What is crucial for our analysis is the position that the pre-verbal accusative object takes in the hierarchical structure in Persian. In Persian, specific accusative objects can be suffixed with a differential object marker (namely -RA). The suffix -RA has been analyzed as a specificity marker (Browne 1970) or a marker conveying presuppositionality, familiarity, and aboutness (Ganjavi 2007). This suffix is absent on the dative object or on the subject. It is generally assumed that -RA marked accusative objects target a higher position in the structure than their non-RA marked counterparts (e.g., Ghomeshi 1996; Karimi 2005; Kahnemuyipour 2009). One piece of evidence that shows that the -RA marked accusative moves to a higher position as compared to the non-RA marked accusative object comes from the position of these elements in double object constructions. This is illustrated in (5) below, taken from Karimi (2005). 

a. Hasan be Maryam ketaab daad. Hasan to Maryam.DAT book.ACC gave 'Hasan gave a book to Maryam.'
b. Hasan ketaab-raa be Maryam daad. Hasan book-RA to Maryam.DAT gave 'Hasan gave the book to Maryam.'

Whereas the non-RA marked accusative object follows the dative object (5a), the -RA marked accusative object undergoes object shift to a higher position above the dative object, as in (5b). We assume that the -RA marked accusative object moves to a vP peripheral position in the spec of a functional projection (such as AgrOP) while the non-RA marked accusative object remains within $\mathrm{VP}$. The hierarchical position of the -RA marked accusative object is illustrated in (6) schematically. At the point of the derivation when $\mathrm{T}$ establishes an Agree relation with the subject in SpecvP, the -RA marked accusative object occupies a position that c-commands the subject in the spec vP position after it is dislocated to the spec AgrOP outside vP. In contrast, the dative object occupies a lower position in the structure, crucially embedded inside a PP, and thus intervening only by precedence.

$$
\left[{ }_{\mathrm{TP}} \mathrm{T} \ldots\left[_{\mathrm{AgrOP}} \text { acc object }-\mathrm{RA} \ldots\left[_{\mathrm{vP}} \text { subject } \ldots[<\text { acc object }>\mathrm{V}]\right]\right]\right]
$$

Persian also allows objects to move to the front of the sentence in structures like topicalization, giving rise to the OSV word order. This is exemplified in (7) in which the -RA marked object is topicalized and thus occurs in the initial position before the subject in the linear order.

$$
\begin{aligned}
& \text { Ketaab-raa Hasan xarid. } \\
& \text { Book-RA Hasan bought } \\
& \text { 'As for the book, Hasan bought it.' }
\end{aligned}
$$

With respect to the derivation of the accusative object in (7), it should be noted that the RA-marked object moves to the spec ArgOP first and then undergoes movement to a higher position, namely the spec Top(ic)P in the left periphery, thus occurring in the clause-initial position (see Mirdamadi 2018 for more details on object movement including wh-movement in Persian). In (7), intervention by the accusative object on Agree is thus the same as in SOV structures because the further movement of the object to the front of the sentence only takes place after the Agree relation has been established.

\subsection{Current study}

An experiment was designed in Persian to explore the role of c-command in attraction in Persian. We contrasted attraction from accusative objects to that of dative objects in canonical SOV as well as in OSV structures involving object movement. If c-command plays a special role in attraction, we expect to replicate the French data from Franck et al. (2010), i.e., stronger attraction with the accusative than with the dative object since the accusative intervenes by c-command on Agree whereas the dative only intervenes by precedence. Moreover, according to the model of Franck et al. (2006; 2010), similar attraction is expected in both SOV and OSV structures, since they both instantiate object intervention on Agree, and not on the Spec-head relation once the subject has moved to its higher position. In contrast, under the hypothesis that attraction is sensitive to linear order and hierarchical structure plays no role, no difference would be expected between 
accusatives and datives, since both occupy a similar linear position with respect to the verb. Moreover, stronger attraction is expected in SOV, in which the object linearly intervenes between the subject and the verb, than in OSV in which the subject and the verb are linearly contiguous.

We used the two-choice response time paradigm with rapid serial visual presentation developed by Staub $(2009 ; 2010)$, in which sentences are presented word by word for a short, fixed period of time (Rapid Serial Visual Presentation) until the verb is reached: at that point, the two verb forms are presented on the screen, and participants have to choose the correct form. This procedure involves a comprehension component (like the classical sentence completion task developed by Bock \& Miller 1991), but still requires that agreement be computed, i.e. that the correct verb be selected. Experimental evidence has shown that this procedure replicates feature mismatch as well as structural effects found with the sentence completion procedure (Franck et al. 2015; Villata et al. 2018; Villata \& Franck 2019). In addition to accuracy, the task allows collecting response times. Hence, following the classical assumption in psycholinguistics that processing difficulty manifests in terms of increased error rates and longer response times, the stronger attraction predicted with accusative objects in SOV and OSV structures is expected to show up in terms of increased error rates and/or increased response times in the data (Staub 2009; 2010).

\section{Experiment \\ 2.1 Method}

\subsubsection{Participants}

Forty Persian native speakers participated in this experiment (age range: 21-37, mean: 26). They were each paid $10 \mathrm{CHF}$ for their participation in the experiment. The study was approved by the Ethics committee of the Faculté de Psychologie at the University of Geneva, and participants signed a consent form before taking part in the experiment.

\subsubsection{Materials}

Three variables were manipulated in a $2 * 2 * 2$ design, involving as variables: Number Match between the subject and the object (Match vs. Mismatch), Object Type (Accusative vs. Dative), and Movement (SOV vs. OSV). The number feature of the subject NP remained singular throughout the experimental items; the object was singular in the match conditions and was plural in the mismatch conditions. Accusative objects all had the suffix -RA while dative objects were introduced by the preposition be ('to') or $b a$ ('with'). In Persian, plural inanimate subjects can optionally occur with singular or plural verbs. We used animate noun phrases (both for subjects and objects) for which subject-verb agreement is obligatory so as to avoid the confounding effect that might arise due to the optionality with plural inanimate NPs. For plural objects, we used quantifiers such as chand taa ('several'), do taa ('two'), or se taa ('three'), where taa is a classifier, and for the singular ones, we used the indefinite article ye ('a/an'). Different verbs were used in the accusative and dative conditions, but we ensured that their number of characters were equated (accusative verbs: $M=6.78, S D=2.28$; dative verbs: $M=6.87, S D=1.96)$. Materials are provided in Appendix.

The experimental items involved 32 item sets with 8 conditions each, giving rise to a total of 256 experimental sentences divided into 8 between-participant lists, such that each participant received 4 items per experimental condition. There were also 64 filler items consisting of various other structures involving clefts, raising constructions and normal declarative SOV sentences. Since all test items had singular subjects, 48 filler items had a plural subject while 16 had a singular one, such that each list had the same number of singular and plural target verb responses. Examples of the experimental items are provided in Table (1). In the experiment, items were presented in Persian alphabet. 
Table 1: Examples of the experimental items in the 8 experimental conditions.

\begin{tabular}{|l|l|l|l|}
\hline ACC & SOV & $\begin{array}{l}\text { Parastaar chand taa/ye mariz-raa did/didand } \\
\text { nurse.SG several.PL/a.SG patient-RA saw.SG/saw.PL } \\
\text { 'The nurse saw several/a patient(s).' }\end{array}$ \\
\hline DAT & SOV & $\begin{array}{l}\text { Parastaar be chand taa/ye mariz } \\
\text { nurse.SG to several.PL/a.SG patient.DAT help did.SG/did.PL } \\
\text { 'The nurse helped several/a patient(s).' }\end{array}$ \\
\hline ACC & OSV & $\begin{array}{l}\text { Chand taa/ye mariz-raa parastaar did/didand } \\
\text { several.PL/a.SG patient-RA nurse.SG saw.SG/saw.PL } \\
\text { 'The nurse saw several/a patient(s).' }\end{array}$ \\
\hline DAT & OSV & $\begin{array}{l}\text { Be chand taa/ye mariz parastaar komak kard/kardand } \\
\text { to several.PL/a.SG patient.DAT nurse.SG help did.SG/did.PL } \\
\text { 'The nurse helped several/a patient(s).' }\end{array}$ \\
\hline
\end{tabular}

\subsubsection{Procedure}

The experiment was carried out through E-prime, using a forced-choice paradigm with RSVP. Words appeared one word at the time in the center of the screen for $250 \mathrm{~ms}$, with $400 \mathrm{~ms}$ interval between each item. At the verb, the two verb forms (singular and plural) were displayed to the left and to the right of the screen (singular to the left, plural to the right), and remained until participants selected their responses. There was no time pressure during the verb selection stage, but participants were instructed to make their responses as accurately and as fast as possible. Before the experimental task started, participants were provided with 16 practice items to help them become fully familiarized with the experimental task. Participants' accuracy and their response time (RT) were measured at the verb selection stage.

\subsubsection{Data analysis}

The effect of Number Match, Object Type and Movement and their interactions on accuracy proportions and RTs were analyzed by way of mixed-effects logistic regressions (to fit accuracy) and linear mixed-effects models (to fit response times), using the lme4 package in R (Bates et al. 2015). Models included as fixed factors Number Match, Object Type, Movement, and their interactions. Maximal models failed to converge, so we conducted model comparisons in order to select the random effects' structure that was best justified by the data, determined on the basis of the Akaike Information Criteria (AIC). We followed a forward selection procedure, starting with random intercepts for participants and items and no random slopes, adding terms successively and selecting the model with the lowest AIC at each step. Since adding random slopes did not result in models with lower AIC, intercept-only models were selected for their greater goodness of fit.

The whole data set consisting of 1280 data points was analyzed without excluding any responses. RTs were analyzed on trials for which participants gave a correct answer and log-transformed to normalize residuals. P-values were calculated by way of the Satterthwaites's approximation to degrees of freedom with the lmerTest package (Kuznetsova, Brockhoff \& Christensen 2016).

\subsection{Results}

Accuracy: Figure 1 illustrates the distribution of accuracy proportions in the eight experimental conditions. Results showed a main effect of Number Match ( $\hat{\beta}=0.865, \mathrm{z}=4.329$, $\mathrm{p}<.001)$, with lower accuracy for the mismatch $(\mathrm{M}=0.84)$ than for the match conditions $(M=0.92)$, and a significant interaction between Number Match and Object $(\hat{\beta}=-1.001$, $\mathrm{z}=-2.513, \mathrm{p}<.01$ ), revealing a significant effect of Number Match for accusatives 


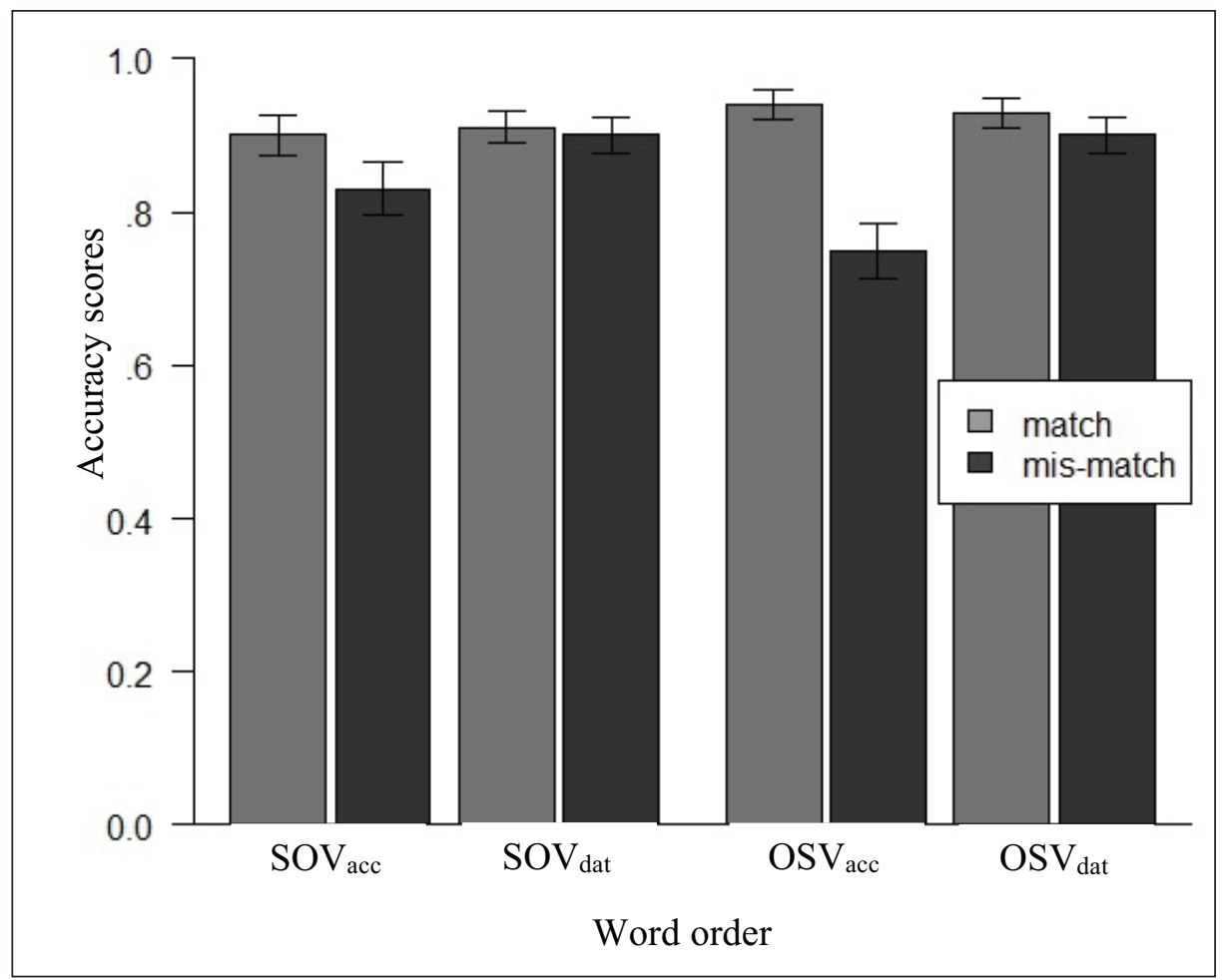

Figure 1: Mean proportion and standard errors of accuracy scores in the 8 experimental conditions.

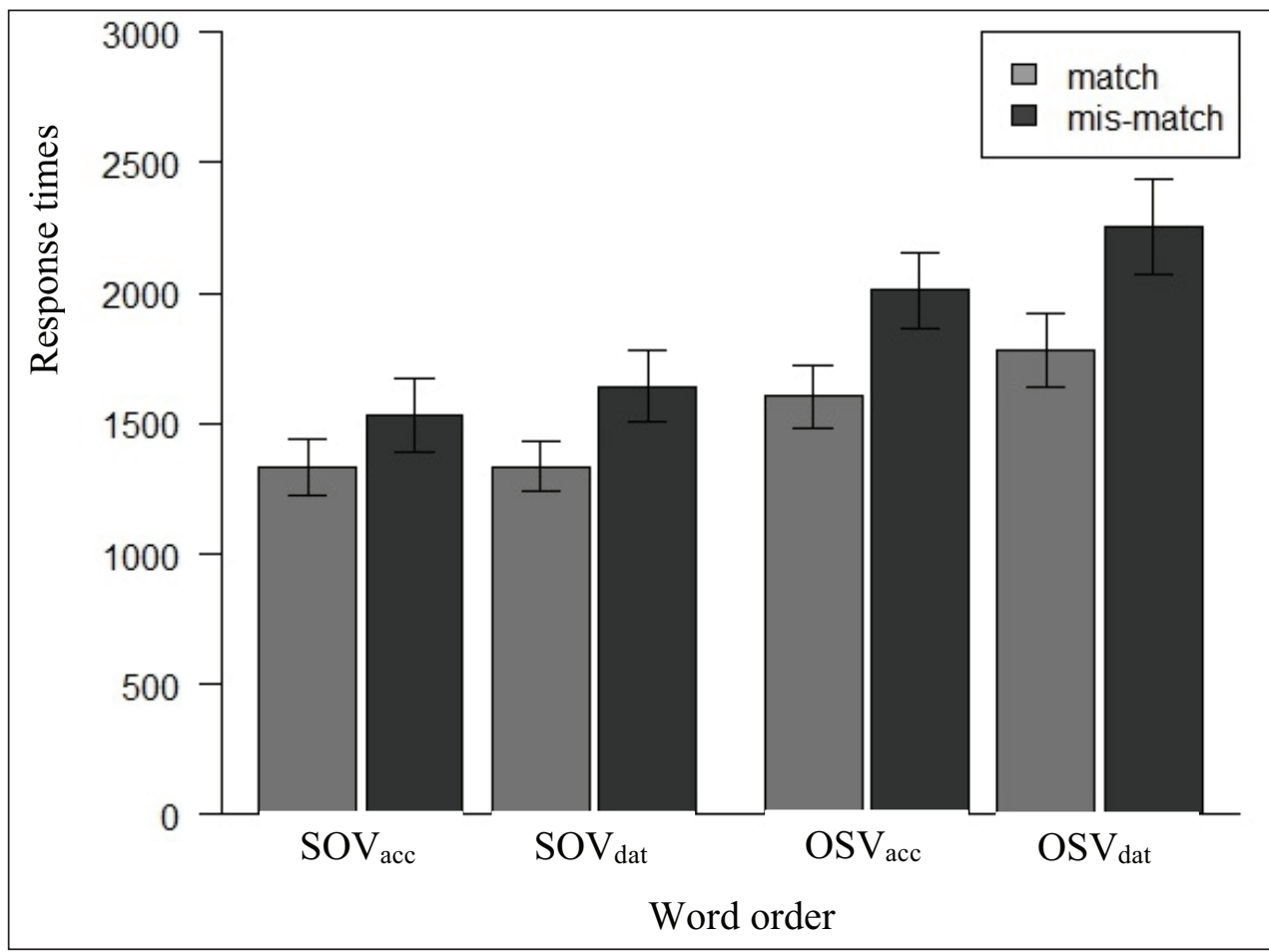

Figure 2: Mean RTs and standard errors for correct responses in the 8 experimental conditions.

( $\widehat{\beta}=1.471, \mathrm{z}=4.832, \mathrm{p}<.001)$, but not for datives $(\widehat{\beta}=0.333, \mathrm{z}=1.169, \mathrm{p}=.243)$. Finally, results showed a marginal interaction between Movement and Number Match $(\widehat{\beta}=-0.714, \mathrm{z}=-1.796, \mathrm{p}=.073)$, attesting to a stronger effect of Number Match in sentences involving movement. No other significant effect was found.

RTs. Figure 2 illustrates the distribution of RTs. Results attested to a main effect of Number Match $(\widehat{\beta}=-0.183, \mathrm{t}=-8.297, \mathrm{p}<.001)$, with slower response times for the 
mismatch conditions $(\mathrm{M}=1861 \mathrm{~ms})$ than for the match conditions ( $\mathrm{M}=1513 \mathrm{~ms})$. A main effect of Movement was also found $(\hat{\beta}=-0.204, \mathrm{t}=-9.233, \mathrm{p}<.001)$ with longer response times when there was movement $(\mathrm{M}=1913 \mathrm{~ms})$ as compared to when there was no movement $(\mathrm{M}=1461 \mathrm{~ms})$. There was a marginal effect of Object ( $\hat{\beta}=0.043$, $\mathrm{t}=1.932, \mathrm{p}=0.054)$ with longer response times for datives $(\mathrm{M}=1754 \mathrm{~ms})$ than for accusatives $(\mathrm{M}=1619 \mathrm{~ms})$. Object significantly interacted with Movement $(\widehat{\beta}=-0.122$, $\mathrm{t}=-2.770, \mathrm{p}<0.01)$, revealing a significant effect of Object in the condition with movement $(\hat{\beta}=-0.111, \mathrm{t}=3.220, \mathrm{p}<0.01)$, but not in the condition without movement ( $\widehat{\beta}=0.002, \mathrm{t}=0.90, \mathrm{p}=0.928)$. No other effect was significant.

\section{Discussion and conclusions}

In this study, we compared attraction errors induced by the accusative object versus the dative object in Persian. The attraction errors induced by these two object types were compared in the canonical SOV word order as well as in the OSV word order in which there was an object movement to the clause-initial position. The main findings can be summarized as follows: (1) we found stronger attraction, manifest in terms of higher sensitivity to the presence of a plural object, with the accusative object than with the dative object, and (2) we found stronger attraction with fronted objects in the OSV word order than with preverbal objects in the canonical SOV word order. We discuss these two findings in turn.

The stronger attraction with the accusative object than the dative object corroborates the prediction of the hypothesis that intervention by c-command on the Agree relation between the subject and the verb perturbs the system more than intervention by precedence. We have followed much of the literature on Persian syntax in assuming that the -RA marked accusative undergoes movement to a position outside vP, e.g. the spec AgrOP position, from which it c-commands the base position of the subject in spec vP. Unlike the -RA marked accusative, the dative object is embedded inside a PP such that it only linearly precedes the subject but does not c-command it. This finding, together with the report in French that preverbal clitic accusatives trigger more attraction than preverbal clitic datives (Franck et al. 2010), shows that two elements that occupy different hierarchical positions but the same surface position in the linear string trigger different attraction rates. It naturally leads to the conclusion that hierarchical structure, and more particularly c-command intervention, plays a key role in attraction, in contrast to the findings of the Scope of planning account (Gillespie \& Pearlmutter 2013).

Our results also showed stronger attraction in OSV compared to SOV, despite the fact that the two structures display the same configuration of object intervention in terms of c-command. A possible explanation for this observation lies in assumptions about the mechanism underlying attraction. Adapting the Feature Selection and Feature Copy model of Franck et al. (2008), and capitalizing on Badecker \& Kuminiak (2007), Franck (2017) suggested that agreement computation involves a process of Feature selection, responsible for selecting phi features on the nouns, and a process of Feature copy, responsible for selecting the agreement controller, i.e. the subject, whose features are copied on the agreement target. In this model, controller selection is the locus of attraction: it operates as a contentaddressable, cue-based mechanism responsible to retrieve the subject from memory on the basis of subject retrieval cues (for a parallel proposal in sentence comprehension, see Wagers et al. 2009 and much of the subsequent literature). The signature manifestation of a cue-based retrieval mechanism is similarity-based interference. Franck (2017) argued that a variety of effects reported in the attraction literature in sentence production could actually be reinterpreted as reflecting similarity-based interference. Experimental evidence shows that stronger attraction arises when the attractor is more similar to the subject 
either semantically (in terms of animacy and overall semantic features, Barker et al. 2001; in terms of thematic roles, Hupet et al. 1998; Thornton \& McDonald 2003), morphologically (in terms of case marking, as attraction is virtually non-existent when the controller and attractor are distinctly case-marked, e.g., Badecker \& Kuminiak 2007; Lorimor et al. 2008; Malko \& Slioussar 2013), and syntactically. In this view, the higher attraction rate observed with c-commanding interveners is due to the fact that c-command is a typical property of subjects, such that elements in a position of c-command are more similar to subjects than those in a position of precedence. Although c-command and hierarchical height fundamentally differ from semantic features and morphological case in that they are relational properties, which poses the problem of how they can be implemented in a content-addressable memory system, potential solutions have been proposed (Kush et al., 2015; Wagers 2008). Interestingly, the presence of -RA on the accusative object does not seem to have served as a cue to the system that this element was not the subject. The Diagnosis model of Fodor \& Inoue (2000) provides a potential framework rendering this aspect of our results compatible with the proposed explanation. In line with the Diagnosis model, we propose that, in contrast to nominative case or the c-commanding position that provide positive cues to subject identification, - $\mathrm{RA}$ is a negative cue in that it cues the object, but not the subject. In other words, -RA says that that element that carries -RA cannot be the subject of the verb, however, it does not say what is the subject. In Persian, since there is no overt nominative case marking on the subject, the subject DP is ambiguous between a subject or a non-RA marked accusative object.

How does this model account for the higher attraction rate we found in OSV compared to SOV structures? We propose that beyond linguistic cues, distributional cues may also play a role in subject retrieval. Subjects typically occupy the first position in Persian sentences. The sentence-first position of the object in OSV may thus provide a misleading cue leading the system to select the object as agreement controller. Recall that the model presented here assumes that attraction arises due to erroneous controller selection, in a structure that is otherwise correctly built. However, another possibility would be that attraction arises due to erroneous structure building, i.e. a structure in which the attractor erroneously occupies the subject position (along the lines of the model of Good Enough Parsing, Ferreira \& Patson 2007). When presented with OSV sentences, participants could erroneously analyze the initial DP as the subject (based on quick and dirty heuristics, like subject-first). This structure building error may then be revised as further elements become available, but in any case, it may linger and affect verb agreement (see Villata et al. 2018 for a description of how structure building takes place and may give rise to attraction). It is beyond the scope of this paper to resolve this question, as the current data do not allow teasing apart the two hypotheses (see Villata et al. 2018 for discussion).

Besides accuracy, our results also provide interesting data with respect to the timing of verb selection. First, we found longer RTs with OSV than SOV, a result that was expected given the well-known penalty due to the processing of sentences involving object movement (e.g., Traxler, Morris \& Seely 2002). Second, we found that number mismatch affected RTs in sentences with accusative objects, but also in sentences with dative objects. In the accusative condition, the longer RTs with number mismatching accusatives aligns well with the increased error rate reported in that condition: the two measures converge in showing that number mismatch creates increased difficulty. In contrast, the number mismatch effect found in RTs for datives does not align with the accuracy measure, which is insensitive to it. One first possibility is that the globally faster RTs found in match conditions simply reflect the fact that participants are careless in these contexts that do not require appropriate structure building or controller selection (since both nouns are singular, the verb will necessarily be singular). Another possibility is that a different 
mechanism from the one we assumed underlies attraction. The Marking and Morphing model of agreement computation (Eberhard et al. 2005) assumes a mechanism of "number valuation" of the subject phrase, operating probabilistically under the conjoined influence of head noun number, attractor number as well as notional factors. In this model, the presence of a local noun with a feature that mismatches the controller's contributes to decrease the quality of the number information available, thus making the process of selecting the verb feature more error-prone. Although the Marking and Morphing model does not make explicit predictions about response times, selecting the subject number under conditions where it is more equivocal may lengthen the decision process, accounting for the longer RTs found in mismatch conditions (Staub 2009).

In any case, the model would need to account for why the mismatch effect appears both in accuracy and RTs for accusatives, but only in RTs for datives, suggesting that accusatives trigger stronger interference than datives. Although in its initial version, Marking and Morphing assumed that only features from the subject phrase had the potential to influence the Morphing process (e.g., Bock \& Cutting 1992; Bock, Eberhard, Cutting, Meyer \& Schriefers 2001), its further formulation allowed any element within a structure to influence it, at a degree that depends on its structural distance from the subject phrase' node (Eberhard et al. 2005). In that view, Marking and Morphing would predict stronger attraction with the accusative than with the dative object, given that it is structurally closer to the agreement controller. In sum, we note that in the face of current evidence, both a mechanism of number valuation and a mechanism of controller selection may be at play in agreement computation, and further research is needed to understand their respective role in attraction.

We also found longer RTs for selecting the correct verb form in sentences with dative objects compared to those with accusative objects in OSV sentences involving movement. Importantly, RTs showed no interaction between Number Match and Object type, i.e., longer RTs were found for datives both in number match and in number mismatch conditions. This indicates that the increased RTs found for datives are not related to the process of number agreement itself, but to some other factor. We explored the potential role of the verbs' internal structure to delineate why RTs were longer in datives as compared to accusatives. Simple verbs and light verbs were used in our experimental materials: while the former are made of a single word (e.g., xaridan, 'to buy'), the latter consist of a nominal, an adjectival, or an adverbial element as well as a light verb (e.g, komak kardan help do, 'to help') (see Karimi-Doostan 1997). Whereas the accusative condition contained 9 light verbs (out of 16), the dative condition contained 14. In order to assess the role of this factor, we re-ran the linear mixed-effects model reported in the Results section including the type of verb (simple vs. light) as an additional predictor. The main effects of Movement and Object number previously reported were preserved, as well as the interaction between Movement and Object type. Verb type failed to interact with Object type $(\widehat{\beta}=-0.067, \mathrm{t}=1.016, \mathrm{p}=0.310)$, or to enter into a triple interaction with Object type and Movement $(\widehat{\beta}=-0.081, \mathrm{t}=-0.761, \mathrm{p}=0.447)$, suggesting that the slower response times found for datives in the OSV condition cannot be attributed to the fact that there were more light verbs in the dative condition. One cannot exclude that the general difficulty with datives is due to increased difficulty in the processing of their information structure, however, more work is needed to explore that hypothesis.

To sum up, Persian offered an interesting test case allowing us to explore, within minimal pair conditions, the role of c-command in attraction. Our results replicated previous findings in French in showing that agreement is a structure-dependent process sensitive to the structural hierarchy. Our finding that occasional performance errors are enhanced when the attractor is in a position of c-command to the subject in its base position, 
compared to when it linearly precedes it, attests to the fundamentally grammar-based nature of the processes underlying attraction. We proposed that attraction arises due to the erroneous identification of the attractor as being the agreement controller, i.e., the subject, and argued that this process of controller selection operates on the basis of subject cues. In this framework, our finding that a c-commanding object triggers more attraction than a preceding object is explained by the fact that c-command is a pointer to subjects, which provides a misleading cue to the process of controller selection. We argued that the process of agreement not only operates under the guidance of linguistic information, but also under the guidance of distributional information, like for example the fact that subjects often occupy the first position in the sentence. The globally higher attraction rate we found for OSV compared to SOV could also be caused by the higher similarity of the object to the subject in OSV compared to the object in SOV, due to its sentence-initial position. The experiment reported here is a first-stab attempt to study attraction phenomena in Persian. Therefore, further experimental and theoretical work is needed in this particular domain, which we hope to pursue in the near future.

\section{Abbreviations}

ACC $=$ accusative, $\mathrm{DAT}=$ dative, $\mathrm{SG}=$ singular, $\mathrm{PL}=$ plural, $\mathrm{PP}=$ prepositional phrase

\section{Additional File}

The additional file for this article can be found as follows:

- Appendix. List of experimental items. DOI: https://doi.org/10.5334/gjgl.804.s1

\section{Ethics and Consent}

The study was approved by the Ethics committee of the Faculte de Psychologie at the University of Geneva, and participants signed a consent form before taking part in the experiment.

\section{Acknowledgements}

We wish to thank Luigi Rizzi, Ur Shlonsky, Whit Tabor, and Sandra Villata for enriching discussions on this work. Nevertheless, we take complete responsibility for the content of the paper.

\section{Funding Information}

The research was funded by the project Complexity, variation and frequence in natural languages: Interfaces between linguistic theory, experimental psycholinguistics and computational linguistics granted to first author Julie Franck, and funded by the Rectorate of the University of Geneva as part of the Réseau thématique Langage et communication.

\section{Competing Interests}

The authors have no competing interests to declare.

\section{References}

Badecker, William \& Frantisek Kuminiak. 2007. Morphology, agreement and working memory retrieval in sentence production: Evidence from gender and case in Slovak. Journal of Memory and Language 56(1). 65-85. DOI: https://doi.org/10.1016/j. jml.2006.08.004

Bates, Douglas, Martin Maechler, Ben Bolker, Steven Walker, Rune Haubo Bojesen Christensen, Henrik Singmann \& Gabor Grothendieck. 2015. Package "lme4". R package version 1.1-10. 
Bock, Kathryn \& Carol Ann Miller. 1991. Broken agreement. Cognitive Psychology 23(1). 45-93. DOI: https://doi.org/10.1016/0010-0285(91)90003-7

Bock, Kathryn \& J. Cooper Cutting. 1992. Regulating mental energy: Performance units in language production. Journal of memory and language 31(1). 99-127. DOI: https://doi. org/10.1016/0749-596X(92)90007-K

Bock, Kathryn, Kathleen M. Eberhard, Cooper Cutting, Antje S. Meyer \& Herbert Schriefers. 2001. Some attractions of verb agreement. Cognitive Psychology 43(2). 83-128. DOI: https://doi.org/10.1006/cogp.2001.0753

Browne, Wayles. 1970. More on Definiteness Markers: Interrogatives in Persian. Linguistic Inquiry 1(3). 359-363.

Eberhard, Kathleen, Cooper Cutting \& Kathryn Bock. 2005. Making sense of syntax: Number agreement in sentence production. Psychological Review 112(3). 531-559. DOI: https://doi.org/10.1037/0033-295X.112.3.531

Ferreira, Fernanda \& Nikole D. Patson. 2007. The 'Good Enough' Approach to Language Comprehension. Language and Linguistics Compass 1(1-2). 71-83. DOI: https://doi. org/10.1111/j.1749-818X.2007.00007.x

Fodor, Janet Dean \& Atsu Inoue. 2000. Syntactic features in reanalysis: positive and negative symptoms. Journal of Psycholinguistic Research 29(1). 25-36. DOI: https://doi. org/10.1023/A:1005168206061

Franck, Julie. 2017. Syntactic encoding: Novel insights into the relationship between grammar and processing. In Eva Fernandez \& Helen Cairns (eds.), The handbook of psycholinguistics. Hoboken, NJ: John Wiley. DOI: https://doi.org/10.1002/9781118829516.ch2

Franck, Julie, Gabriela Soare, Ulrich H. Frauenfelder \& Luigi Rizzi. 2010. Object interference: The role of intermediate traces of movement. Journal of Memory and Language 62(2). 166-182. DOI: https://doi.org/10.1016/j.jml.2009.11.001

Franck, Julie, Gabriella Vigliocco \& Janet L. Nicol. 2002. Attraction in sentence production: The role of syntactic structure. Language and Cognitive Processes 17(4). 371-404. DOI: https://doi.org/10.1080/01690960143000254

Franck, Julie, Glenda Lassi, Ulrich H. Frauenfelder \& Luigi Rizzi. 2006. Agreement and movement: a syntactic analysis of attraction. Cognition 10(1). 173-216. DOI: https:// doi.org/10.1016/j.cognition.2005.10.003

Franck, Julie \& Matthew Wagers. 2015. Hierarchical structure and memory retrieval mechanisms in attraction: An SAT study. Poster presented at the CUNY conference on sentence processing, Los Angeles, March 19-21.

Franck, Julie, Stephany Cronel-Ohayon, Laurence Chillier, Ulrich H. Frauenfelder, Cornelia Hamann, Luigi Rizzi \& Pascal Zesiger. 2004. Normal and pathological development of subject-verb agreement in speech production: A study on French children. Journal of Neurolinguistics 17(2). 147-180. DOI: https://doi.org/10.1016/S09116044(03)00057-5

Ganjavi, Shadi. 2007. Direct Objects in Persian. Los Angeles, CA: University of Southern California dissertation.

Ghomeshi, Jila. 1996. Projection and Inflection: A Study of Persian Phrase Structure. Toronto: University of Toronto dissertation.

Gillespie, Maureen \& Neal J. Pearlmutter. 2013. Against structural constraints in subjectverb agreement production. Journal of Experimental Psychology: Learning, Memory, and Cognition 39(2). 515-528. DOI: https://doi.org/10.1037/a0029005

Hartsuiker, Robert, Inés Antón-Méndez \& Marije van Zee. 2001. Object attraction in subject-verb agreement construction. Journal of Memory and Language 45(4). 546-572. DOI: https://doi.org/10.1006/jmla.2000.2787 
Hupet, Michel, Michel Fayol \& Marie-Anne Schelstraete. 1998. Effects of semantic variables on the subject-verb agreement processes in writing. British Journal of Psychology 89(1). 59-75. DOI: https://doi.org/10.1111/j.2044-8295.1998.tb02673.x

Kahnemuyipour, Arsalan. 2009. The Syntax of Sentential Stress. Oxford: Oxford University Press. DOI: https://doi.org/10.1093/acprof:oso/9780199219230.001.0001

Karimi, Simin. 2005. A Minimalist Approach to Scrambling: Evidence from Persian. Berlin, New York: Mouton de Gruyter. DOI: https://doi.org/10.1515/9783110199796

Karimi-Doostan, Gholamhossein. 1997. Light Verb Constructions in Persian. Colchester: University of Essex dissertation.

Kayne, Richard. 1989. Romance clitics, verb movement and PRO. Linguistic Inquiry 22. 647-686.

Kayne, Richard. 1994. The antisymmetry of syntax. Cambridge/London: the MIT press.

Kimball, John \& Judith Aissen. 1971. I think, you think, he think. Linguistic inquiry 2(2). 241-246.

Kush, Dave, Jeffrey Lidz \& Collin Phillips. 2015. Relation-sensitive retrieval: Evidence from bound variable pronouns. Journal of memory and language 82. 18-40. DOI: https:// doi.org/10.1016/j.jml.2015.02.003

Kuznetsova, Alexandra, Per Brockhoff \& Rune Haubo Christensen. 2015. Package 'ImerTest'. $R$ package version 2-0.

Lorimor, Heidi, Kathryn Bock, Ekaterina Zalkind, Alina Sheyman \& Robert Beard. 2008. Agreement and attraction in Russian. Language and Cognitive Processes 23(6). 769-799. DOI: https://doi.org/10.1080/01690960701774182

Malko, Anton \& Natalia Slioussar. 2013. Attraction errors in gender agreement: Evidence from Russian. In Steven Franks, Markus Dickinson, George Fowler, Melissa Whitcombe \& Ksenia Zanon (eds.), Formal Approaches to Slavic Linguistics: The Third Indiana Meeting, 162-175. Ann Arbor, MI: Michigan Slavic Publications.

Rizzi, Luigi. 1990. Relativized Minimality. Cambridge, Mass: MIT Press.

Rizzi, Luigi. 2013. Notes on cartography and further explanation. International Journal of Latin and Romance Linguistics 25(1). 197-226. DOI: https://doi.org/10.1515/probus-2013-0010

Staub, Adrian. 2009. On the interpretation of the number attraction effect: Response time evidence. Journal of Memory and Language 60(2). 308-327. DOI: https://doi. org/10.1016/j.jml.2008.11.002

Staub, Adrian. 2010. Response time distributional evidence for distinct varieties of number attraction. Cognition 114(3). 447-454. DOI: https://doi.org/10.1016/j.cognition.2009.11.003

Thornton, Robert \& Maryellen MacDonald. 2003. Plausibility and grammatical agreement. Journal of Memory and Language 48(4). 740-759. DOI: https://doi.org/10.1016/ S0749-596X(03)00003-2

Travis, Lisa. 1991. Parameters of Phrase Structure and V2 Phenomena. In Robert Freidin (ed.) Principles and Parameters in Comparative Grammar. Cambridge, MA: MIT Press.

Vigliocco, Gabriella \& Janet Nicol. 1998. Separating hierarchical relations and word order in language production: is proximity concord syntactic or linear? Cognition 68(1). B13-B29. DOI: https://doi.org/10.1016/S0010-0277(98)00041-9

Villata, Sandra, \& Julie Franck. 2019. Similarity-based interference in agreement comprehension and production: Evidence from object agreement. Journal of Experimental Psychology: Learning, Memory, and Cognition. DOI: https://doi.org/10.1037/xlm0000718

Villata, Sandra, Whitney Tabor \& Julie Franck. 2018. Encoding and retrieval interference in sentence comprehension: Evidence from agreement. Frontiers in Psychology. DOI: https://doi.org/10.3389/fpsyg.2018.00002 
Wagers, Matthew. 2008. The structure of memory meets memory for structure in linguistic cognition. University of Maryland dissertation.

Wagers, Matthew, Ellen Lau \& Collin Phillips. 2009. Agreement attraction in comprehension: Representations and processes. Journal of Memory and Language 61(2). 206-237. DOI: https://doi.org/10.1016/j.jml.2009.04.002

How to cite this article: Franck, Julie, Farhad Mirdamadi and Arsalan Kahnemuyipour. 2020. Object attraction and the role of structural hierarchy: Evidence from Persian. Glossa: a journal of general linguistics 5(1): 27.1-17. DOI: https:// doi.org/10.5334/gjgl.804

Submitted: 15 September 2018

Accepted: 18 August 2019

Published: 09 March 2020

Copyright: $\odot 2020$ The Author(s). This is an open-access article distributed under the terms of the Creative Commons Attribution 4.0 International License (CC-BY 4.0), which permits unrestricted use, distribution, and reproduction in any medium, provided the original author and source are credited. See http://creativecommons.org/licenses/by/4.0/.

Glossa: a journal of general linguistics is a peer-reviewed open access journal published by Ubiquity Press.

OPEN ACCESS $\boldsymbol{\sigma}$ 